Nueva Revista de Filología Hispánica (NRFH), LXVI, 2018, núm. 2, 627-649

ISSN 0185-0121; e-ISSN 2448-6558; DOI: 10.24201/nrfh.v66i2.3428

\title{
LÉXICO NOVOHISPANO EN EL VOCABULARIO DE ANTONIO DE ALCEDO
}

\section{LEXICON FROM NEW SPAIN IN ANTONIO DE ALCEDO'S VOCABULARY}

\author{
Sofía Kamenetskaia \\ Universidad Autónoma de la Ciudad de México \\ sokakot@hotmail.com
}

Resumen: Entre 1786 y 1789, Antonio de Alcedo publicó el Diccionario geográficohistórico de las Indias Occidentales o América, que en el quinto volumen incluye como anexo el repertorio de las voces americanas. En el presente trabajo, se revisan los vocablos alusivos a Nueva España en el Vocabulario que contienen información sobre flora, fauna y vida cotidiana de este gran territorio virreinal, todo lo cual resulta por demás significativo para los estudios de lexicografía regional americana y, particularmente, mexicana.

Palabras clave: Antonio de Alcedo; Diccionario; Vocabulario; léxico novohispano; lexicografía regional.

Abstract: Between 1786 and 1789 Antonio de Alcedo published the Diccionario geográfico-histórico de las Indias Occidentales o de América, whose fifth volume includes an annex containing the repertoire of the American voices. The present paper analyzes the words referring to New Spain included in the Vocabulary. Inasmuch as they provide information on the flora, fauna and daily life of this great vice regal territory, these words are very significant for the study of American, and especially Mexican, regional lexicography.

Keywords: Antonio de Alcedo; Dictionary; Vocabulary; New Spanish Lexicon;

Regional Lexicography.

Recepción: 16 de marzo de 2017; aceptación: 19 de octubre de 2017.

D.R. ( ) 2018. Nueva Revista de Filología Hispánica Licencia Creative Commons Attribution-NonCommercial (CC BY-NC) 4.0 International 


\section{INTRODUCCIÓN}

Entre 1786 y 1789, Antonio de Alcedo publicó su Diccionario geográfico-histórico de las Indias Occidentales o América en cinco volúmenes, en el cual ofreció, con toda la información que consideró pertinente, una descripción enciclopédica muy detallada de los territorios americanos pertenecientes a la Corona española, como indica el título completo de su trabajo ${ }^{1}$. Aunque por la importancia de su labor, Alcedo ingresó a la Real Academia de Historia en 1787 como miembro correspondiente ${ }^{2}$, su Diccionario no contó con la suficiente difusión en España por el temor -primero de Carlos III y después de Carlos IV, a quien fue dedicado el Diccionario- de que la información contenida en este libro llegara a otras naciones, principalmente a Inglaterra, que, movidas por la codicia, pudieran ocasionar graves conflictos a la monarquía española (Barros Arana 1863, pp. 497-498), de ahí que su venta y circulación se interrumpieran ${ }^{3}$. Este temor fue confirmado por George Alexander Thompson, traductor inglés del ejemplar, quien, motivado por el interés y la utilidad de la obra, la editó en Londres entre 1812 y $1815^{4}$. No obstante la preocupación de la Corona, el ejemplar se difundió en América, donde, según José de Onís (1951), gozó de gran popularidad e influencia ${ }^{5}$ y fue considerado "obra patriótica" (pp. 532-533).

Diego Barros Arana (1863, pp. 496-497) comenta que, a pesar de las minuciosas descripciones geográficas, con sus reseñas históricas de cada provincia, obispado, ciudad y listas cronológicas de los gober-

${ }^{1}$ Véase el título completo en la bibliografía del artículo. Creo conveniente, sin embargo, anotar aquí cuándo fueron publicados los volúmenes de que consta la obra: $1^{\circ}$, Imprenta de Benito Cano, 1786; $2^{\circ}$, Imprenta de Manuel González, 1787; $3^{\circ}$, Imprenta de Blas Román, $1788 ; 4^{\circ}$, Imprenta de Manuel González, $1788 ; 5^{\circ}$, Imprenta de Manuel González, 1789.

2 Para su actividad académica, véase el estudio preliminar de Ciriaco PérezBustamante 1967, t. 1, especialmente pp. xxiv-xxix.

${ }_{3}$ Alcedo, en el t. 1 de su Diccionario, proporciona una lista pormenorizada de sus suscriptores, que llegaban a 196. Véanse en Antonio de Alcedo $(1786$, t. 1) la "Lista de las Personas que han subscrito por los seis primeros Quadernos de este Diccionario", pp. xi-xvi, y la "Continuación de la lista de suscriptores á este Diccionario", pp. 787-791.

${ }^{4}$ Barros Arana (1863, p. 499) señala que la traducción inglesa tiene varios errores por falta de conocimiento de la lengua española y da un ejemplo: Thompson recogió la voz ministro con el significado de 'religioso', 'miembro del clérigo, especialmente, en la iglesia protestante', y no según el sentido que le había dado Alcedo: 'persona que forma parte del gobierno de un Estado como responsable máximo de un ministerio'.

${ }^{5}$ Palabras contradictorias, ya que, de acuerdo con mi conteo de suscriptores americanos, de los que pude averiguar a partir de sus explicaciones fueron solamente 12. No obstante, como Alcedo en la lista de sus suscriptores no siempre especifica el puesto o el lugar de la residencia de sus compradores, es complicado saber con exactitud cuántos de ellos radicaban en América. 
nadores, la obra de Alcedo contiene numerosos errores que emanan de las fuentes consultadas, entre las que destacan obras publicadas más de treinta años antes de su Diccionario. Además, el intelectual chileno habla de los equívocos constantes y repetitivos en la descripción de las ciudades y en el orden de los gobernadores y obispos, pues su autor no actualizó los datos ni llenó casillas vacías. De hecho, el mismo Alcedo, quien revisó "más de 300 libros de Indias" (1786, t. 1, p. viii), advirtió en el prólogo que trató de reducir los yerros al mínimo, por lo que agregó a su primer tomo adiciones y correcciones. Aunado a lo anterior, y sin importar las limitaciones que el propio Alcedo reconoce, coincido en que se trata de un monumento cultural del siglo XviII que permite entender "la atmósfera intelectual e ideológica de la Ilustración en el mundo hispánico” (Lerner, 1982, p. 117).

Como Alcedo consultó muchos materiales concernientes a América, pretendía proporcionar referencias y autores en tomo aparte, obra que finalmente completó en 1791 con el título de Bibliotheca Americana ${ }^{6}$ y que Publicaciones del Museo Municipal de Arte e Historia de Quito ${ }^{7}$ editó en los años sesenta del siglo pasado ${ }^{8}$.

\section{Objetivo y Metodología}

El quinto y último tomo fue complementado con el Vocabulario que contenía la "lista alfabética de los nombres provinciales y voces extrañas de frutas, árboles, animales, \&c" (Alcedo, 1786, t. 1, p. ix), y debe

6 Título completo del manuscrito: Bibliotheca americana. Catálogo de los autores que han escrito de la América en diferentes idiomas, y noticia de su vida, patria, años en que florecieron, i obras que dejaron escritas, por el Coronel don Antonio de Alcedo, capitán de reales guardias españolas, académico de la Real Academia de Historia, MDCCXCI, Bibliotheque Nationale, Manuscrits de la Collection Angrand. José de Onís revela que este manuscrito ológrafo está incompleto, ya que hay una segunda copia del puño y letra de Alcedo con fecha de 1807, propiedad de Lenox y donada luego a la Biblioteca Pública de Nueva York, cuyo título es Bibliotheca Americana. Catálogo de los Autores que han escrito de la América en diferentes Idiomas, y Noticia de su Vida y Patria, años en que vivieron, I Obras que escribieron, compuesta por El Mariscal de Campo D. Antonio de Alcedo, Gobernador de la Plaza de la Coruña. Año de 1807. Cf. José de ONís 1951, pp. 534-536.

7 Aunque el ejemplar fue editado en 1964, no me ha sido posible consultarlo en México. El historiador Roberto Moreno (1970, p. 220) puntualizó en su reseña de este trabajo que Alcedo se basó en más de dos mil autores y una larga lista de obras anónimas, cuya revisión sería por demás significativa para el presente artículo.

${ }^{8}$ Cabe destacar también que hay varias copias manuscritas de la obra en distintas bibliotecas del mundo. Para saber más acerca del manuscrito, sus distintos poseedores y las copias, véanse Diego Barros Arana 1863, José de Onís 1951 y Gonzalo ZALDUMBIDE 1960. 
considerarse como el primer diccionario del léxico americano ${ }^{9}$. Por consiguiente, el propósito de este trabajo es examinar los vocablos que en el Vocabulario aluden a Nueva España y analizar su tratamiento. Para contar con la revisión objetiva y concluyente de este repertorio léxico, se comparará con los datos del Corpus diacrónico del español, fuente que aporta mayores elementos para el estudio histórico del español novohispano.

El número de vocablos que Alcedo incluye en este diccionario varía, de acuerdo con los lingüistas que se han ocupado de analizarlo; así, Manuel Alvar Ezquerra (2005, p. 15) proporciona la cantidad de 629 voces, mientras que Isaías Lerner (1982, p. 120), la de 634. Mis cálculos, en cambio, sugieren una cifra poco mayor: 645 palabras americanas en total. Según demanda el propósito de este trabajo, se recogieron los vocablos que referían al territorio novohispano por su cercanía geográfica a lo que sería México después. En este sentido, hay que aclarar que en el tiempo en que Alcedo redactó y publicó el fruto de su largo e ingente trabajo, el Virreinato de Nueva España abarcaba no sólo el territorio que hoy ocupa la República mexicana, sino zonas mucho más amplias. El historiador Edmundo O’Gorman le atribuyó las siguientes especificaciones geográficas:

El Virreinato de Nueva España fue parte de la Monarquía Española en la América del Norte, Centroamérica, Asia y Oceanía. Fue establecido tras la conquista del Imperio azteca, realizada entre 1519 y 1521 por las tropas de Hernán Cortés, por decreto real del rey español Carlos I, del 1 de enero de 1535, aunque la instauración oficial se realizó el 8 de marzo.

La Nueva España estaba comprendida por el actual México, más los actuales estados de California, Nevada, Colorado, Utah, Nuevo México, Arizona, Texas, Oregón, Washington, Florida y partes de Idaho, Montana, Wyoming, Kansas, Oklahoma y Luisiana, por parte de los actuales Estados Unidos de América; así como la parte suroeste de Columbia

${ }^{9}$ A finales del siglo xx, Miguel Ángel Quesada Pacheco encontró en la Biblioteca Real de Madrid el manuscrito del panameño Manuel José de Ayala, recopilador de leyes de Indias y archivero de la Secretaría de Estado y del Despacho Universal de Indias, escrito probablemente entre 1751 y 1777, y lo publicó en 1995 bajo el título de Diccionario de voces americanas. Aunque se trata de una obra de suma importancia que reúne aproximadamente 2800 entradas, cantidad mayor a la recopilada por Alcedo, que corresponden a indigenismos (630), palabras de origen castellano de la flora y la fauna, la minería y la vida cotidiana que adquirieron significado distinto en América, este diccionario pasó inadvertido en su tiempo, por lo que no pudo constituirse en antecedente de los posteriores escritos sobre el tema. Cf. Miguel Ángel Quesada Pacheco, "Prólogo", en Manuel José de Ayala 1995, pp. ix-xlvii. Además, según Günther Haensch (1994, pp. 39 y 43), el Vocabulario de Alcedo es el punto final de la prehistoria de la lexicografía del español de América y, al mismo tiempo, el punto de partida de su historia propiamente dicha, es decir, "marca la transición a la lexicografía moderna". 
Británica del actual Canadá; más la Capitanía General de Guatemala (comprendida por los actuales países de Guatemala, Belice, Costa Rica, El Salvador, Honduras y Nicaragua); más la Capitanía General de Cuba (actuales Cuba, República Dominicana, Puerto Rico, Trinidad y Tobago y Guadalupe); así como, finalmente, la Capitanía General de las Filipinas, (comprendiendo las Filipinas, Carolinas y las Marianas, en el Pacífico asiático), fueron todos estos territorios partes constitutivas del Virreinato de Nueva España (1985, pp. 13-15).

Según esta clasificación territorial, además de los vocablos que hacen referencia a Nueva España, que son la mayoría, o a alguna de sus regiones, como Tabasco, Campeche, Sinaloa, Michoacán y Oaxaca, tendríamos que recoger los de la Isla de Santo Domingo, de las provincias de Florida, California y Nuevo México, en la América Septentrional; Vera Paz, en el Reino de Guatemala, así como los de las islas de Jamaica, Guadalupe, Trinidad y Cuba, en las Antillas. No obstante, ya que me baso en la obra compuesta por Alcedo, me pareció más adecuado seguir su división territorial. Aunque el autor no recoge como entrada el artículo correspondiente a Nueva España, al final del quinto volumen (1789, pp. 1-7), y antes de empezar el Vocabulario, presenta un resumen de los reinos y provincias en que está dividida la América española, donde además habla de los territorios que conforman las dos Américas, Septentrional y Meridional. Según este esquema, al precisar la separación geográfica de la América Septentrional, Alcedo (pp. 4-7) especifica que esta parte cuenta con sólo un Virreinato (de la Nueva España) y que comprende los siguientes reinos y provincias:

Reyno de la Nueva España. Gobiernos: Vera-Cruz, Acapulco, Coaguila, Puebla de los Ángeles, Yucatán, Tabasco. Alcaldías mayores: Actopam, Apam, Acayuca, Antigua, Acatlán, Atrisco, San Blas, Chalco, Cuyoacán, Chietla, Chiautla, Coatepec, Cozamaluapan, Córdoba, Cadreita, Chilapa, Cuernavaca, Colima, Cholula, Chiguagua, S. Cristoval, Ezatlan, Guijolotitlán, Huamelula, Huajuapan, Huichiapan, Huelutla, Guejotzinco, Ixtepexi, Ixtlahuaca, Izúcar, Ixmiquilpan, Justláhuac, S. Juan de los Llanos, Lerma, Mexilcaltzinco, Miahuatlan, Metepec, Malinalco, Mextitlán, Nexapa, Nochiztlán, Nuevo Santander, Oaxaca, Orizava, Otumba, Papantla, Quatro Villas, Quantla Amilpas, Quautitlán, Querétaro, Temastelpec, Tepeaca, Tecali, Tehuacán de las Granadas, Teutitlán, Teutila, Tehuantepec, Teocuilco, Tepozcolula, Tepexi de la Seda, Tacuba, Toluca, Tenango del Valle, Tetela del Río, Taxco, Tixtla, Tochimilco, Tula, Tetepango, Tehusitlán, Tampico, Tulanzinco, Tetela Xonotla, Tezcuco, Teotihuacan, Tlaxcala, Tuxtla, Tlapa, Villalta, Valladolid, Valles, Xalapa, Xuchimilco, Xicayan, Yahualica, Zacualpan, Zapotlán, Zumpango, Zimapan, Zacatlán de las Manzanas, Zempoala, Zimatlam. 
Reyno de Mechoacán. Alcaldías mayores: Cuiceo de la Laguna, Guimeo, Guanajuato, San Luis de Potosí, San Luis de la Paz, Maravatio, San Miguel el Grande, Tancitaro, Tlasasalca, Tlalpujagua, Villa de León, Xiquilpa, Zelaya, Pásquaro, Chaco, Guadalcazar, Jaso y Teremendo, Chilchota, Zamora, Cinaque, Motines, Tinguindín, Xiquilpa, Zacatula.

Reyno de Nueva Galicia. Alcaldías mayores: Amula, Autlán, Zayula, Zacatecas, Guadalaxara, Tala, Tepic, Sentipac, Tequepexpa, Tonalá, Ostotipaquillo, Analco, Mazapil, Aguas Calientes, Zapopan, Xala, Caxititlán, Tlajomulco, Zapotlán, Izatlán, Guauchinango, Purificación, Ostotipac, Compostela, Acaponeta, Nayarith, Barca, Tecpatitlán, Lagos, Cuquio, Tecualtichi, Juchipila, Colotlán, Xerez, Fresnillo, Ibarra, Sierra de Pinos, Charcas.

Asimismo, advierte que la "Capitanía General de la Isla de Cuba que abarca los Gobiernos de Cuba, Florida y Luisiana no forman parte del Virreinato de la Nueva España" (1789, t. 5, pp. 4-7); en otras palabras, el territorio que nos ocupa estaba compuesto por tres reinos divididos en seis gobiernos y 155 alcaldías mayores. Como se puede apreciar a partir de estas clasificaciones, el cuadro geográfico de Alcedo abarca menor territorio que el de O'Gorman, por lo cual creo que la cantidad de vocablos novohispanos que se puede obtener de la lista de nuestro autor es más reducida. Como el autor ofrece el uso geográfico de todas sus voces, la metodología para conformar el corpus de mi estudio se estableció recogiendo aquellas voces que hacen referencia exclusivamente a Nueva España, como:

ALBURES. Juego de cartas semejante al de parár, muy usado en Nueva España, donde se juega con exceso.

CACHUPÍN. Nombre que dan en Nueva España á los Europeos.

COYÓTE. Voz genérica que se da á las producciones de la tierra, o sea del país en Nueva España, como Indio coyote, Lobo coyote, Cidra coyote.

También se recogieron las voces que refieren a alguna provincia, alcaldía mayor o a algún lugar en el Virreinato de la Nueva España:

QUINTE. Animal quadrúpedo de la especie de los Gamos, aunque más pequeño del Reyno de Nueva España, y particularmente de la provincia de Tabasco.

MIXE. Es pecie de tabaco silvestre diferente del conocido, que se cría en la Provincia de Villalta en Nueva España.

Asimismo, las voces que aluden a Nueva España, aunque también se emplean en otros territorios americanos:

BOBO. Pez muy común en los ríos de Nueva España y América Septentrional... 
COPAL (Copalifera). Goma que se saca por incisión de un árbol muy grueso que tiene las hojas largas, anchas y puntiagudas, y el fruto semejante al membrillo... La madera del árbol sirve para hacer mesas, sillas, escritorios, \&. tiene mucha estimación, y lo hay en Nueva España, en la provincia de Esmeraldas del Reyno de Quito y en otras partes.

Excluyo de esta lista el vocablo temepechín, ya que la alcaldía mayor de Suchitepeque no figura, según el cuadro del propio Alcedo, dentro de las alcaldías del Virreinato de la Nueva España; tampoco la incluye como de origen novohispano en la entrada de esta provincia en su Diccionario:

SUCHITEPEQUE. Provincia y Alcaldía mayor del Reyno de Guatemala, confina por el N con la de Sololá y Aitán, por el O con la de Soconusco, por el Sur con el mar Pacífico, á cuya orilla se extiende su jurisdicción... sus principales frutos son el cacao, achote, vainilla y otras drogas, de que hace un gran comercio con la Nueva España por tierra, y con los Reynos de Tierra Firme y el Perú por los Puertos de la mar del Sur...: riéganla [esta Alcaldía] diferentes ríos..., en todos ellos abunda el pescado que es de excelente calidad, y con preferencia el que llaman los Indios temepechín, que tiene singular aprecio... (1788, t. 4, s.v.).

Sin embargo, en su definición él mismo adjudica la voz a este Virreinato:

TEMEPECHÍN. Pez exquisito y regalado que se pesca en los Ríos de la Alcaldia mayor de Suchitepeque en Nueva España.

\section{REVISIÓN DEL LÉXICO NOVOHISPANO}

\section{Preliminares}

El caso del vocablo temepechin, arriba mencionado, puede considerarse como una de las inconsistencias del trabajo de Alcedo, pero no la única. En la revisión del léxico novohispano se encuentran otras, concernientes tanto a forma como a contenido. En cuanto a las del primer tipo, destaca la incoherencia de la voz dezcál, que aparece en la letra M y no D, aunque la obra es semasiológica, y remite al 'maguey', por lo cual creo que debe referirse a la voz mezcal. Tal vez se trate de un error tipográfico, si se juzga por lo que sucede con otra voz, oleacazán, que presenta errores de impresión con respecto a las obras lexicográficas y botánicas consultadas ${ }^{10}$, que sólo recogen olcacazán/

10 Rēmi Simēon 1981, s.v.; Luis Cabrera 1974, s.v.; Francisco Javier SantamaRía 1992, s.v.; Francisco Hernández 1946, t. 3, cap. 73, pp. 766-767, y MaXimino MARTínez 1994, s.v. 
olcacatzin, y según las explicaciones que se dan en estos repertorios, se trata de la misma planta perteneciente a idéntica especie; evidentemente, esta errata es producto de la semejanza entre las letras $e$ y $c$.

Las inconsistencias lexicográficas que llaman la atención empiezan por el vocablo quapaxtle, que suscita discusión por su forma y que Alcedo define así: "Yerba aromática y olorosa de Nueva España, que cultivan y usan mucho, especialmente en la Jurisdicción de Malinalco para llevarla á México y otras partes". Esta voz, tal como la escribe Alcedo, no se registra ni en los repertorios lexicográficos ni botánicos. Alonso de Molina, por ejemplo, únicamente recoge la voz quappach$t l i$, con el significado de 'color leonado o medio morado' (2001, s.v.), mientras que Rēmi Simēon, para el sentido 'planta', proporciona quapatlachtli: "planta silvestre de la familia aráquida", aludiendo, como su referente, a Bernardino de Sahagún. Santamaría, quien cita a Robelo, menciona el vocablo coapascle: "Genéricamente se dice del heno, el musgo y toda parásita análoga a éstas, que se cría sobre los árboles y las piedras". Sólo Marcos E. Becerra recoge el vocablo con una escritura parecida y con el significado de la planta:

CUAPAXTLE (del nahoa kua-pachtli, de kuahuitl, árbol, i pachtli, parásito). Sust. m. Méx. Hierba epifita, americana, de la familia de las Bromeliáceas (Tillandsia usneoides, L.), de tallos filamentosos, mui largos, de color verde cenizo, i que cuelgan, a manera de cabellera, de los árboles de que son parásitos, especialmente de los ahuehuetes. En México se utiliza mucho como adorno, particularmente en los altares de Navidad o nacimientos. En otras partes sirve para rellenar cojines i colchones.

Hallo este nombre en Robelo, aunque afeado en la forma de "cuapascle". También llamado "PASTE", "PAXTLE", "HENO" i "SALVAGINA" (1984, p. 206).

Con respecto a las obras botánicas, Francisco Hernández, a quien consultó nuestro autor -y quien, bajo el nombramiento de Protomédico del Nuevo Mundo y con la encomienda del rey Felipe II de describir las plantas, animales y minerales útiles a la Corona espanola, recorrió gran parte del territorio novohispano, especificando más de 3000 especies de plantas y 500 de animales ${ }^{11}$-, da entrada a la voz coapatli, explicándola de esta manera:

El COAPATLI origanoide es una hierba de casi cuatro codos de largo, raíz fibrosa, hojas como de almendro, florecillas escarlata contenidas en cápsulas y gusto amargo, oloroso y acre. Es caliente y seco en tercer grado, y quita la flatulencia aplicado de cualquier manera. Se parece al orégano en el olor, el sabor y la forma, por lo que podría tal vez, con razón, clasificarse entre sus especies.

${ }^{11}$ M. Hilda Flores Olvera, "Presentación...". 
Coapahtli: de coa $(t l)$, culebra, y pahtli, medicina.

Medicina de culebra.

Lippia umbellata Cav. $^{12}$

Parece extraño que Alcedo no ofrezca esta forma ni proporcione ningún comentario al respecto, ya que en otras definiciones de plantas siempre hace explícito si en algo no coincide con este botánico, como se verá más adelante.

Con Hernández está de acuerdo Maximino Martínez (1994, p. 191) al afirmar que los autores de la época colonial escribían con la letra $q$ los nombres en que había el elemento cuáhuitl, que significa árbol en la lengua náhuatl, por lo que en su Catálogo de nombres vulgares y científicos de plantas mexicanas, estas palabras se encuentran en la letra $c$; por ende, la planta que nos ocupa es coapatli:

Coapatli. (Lengua azteca, Veracruz).

Commelina coelestis Willd. y otras especies; Comelináceas (Ramírez y Alcocer).

Otra incongruencia se halla en el vocablo chico zapote, que se recoge como locución en vez de una sola palabra, cuya definición se asigna equivocadamente a la planta española nispero (Flores Olvera y R. Lindig-Cisneros 2005, t. 76, pp. 26 y 28), aunque se trata de especies distintas que pertenecen a géneros diferentes: la planta nativa chicozapote, cuyo nombre científico es achras sapota, corresponde al género sapotáceas, mientras que el níspero (mespilus germánica), introducido a este territorio, es del género rosáceas.

También hay otro caso peculiar por cuanto Alcedo da en una entrada independiente el nombre del mismo pez que aparece como variante: así, tenemos la entrada de charál o mistlapic frente al lema miztlapique. El autor lo presenta de esta manera:

CHARÁL ó MISTLAPIC. Nombres sinónimos que dan en la Nueva España al pez Peje Rey, de que hacen gran comercio.

MIZTLAPIQUE. Pez pequeñito y muy regalado que abunda en la Laguna de México: es del tamaño de un dedo, y semejante á los dorados.

Sin embargo, mistlapicy miztlapique, de origen náhuatl, son variantes, como observa Santamaría:

Charal. (Del tarasco charare). m. Pececillo de dos pulgadas de largo, muy delgado y espinoso, que se cría en abundancia en las lagunas del estado de Michoacán, y curado al sol es artículo de comercio. V. MEZTLAPIQUE.

Meztlapique. m. Mesclapique.

${ }^{12}$ Francisco Hernández, 1942, t. 1, cap. 95, p. 233: "Del COAPATLI origanoide". 
Mesclapique. (Del azt.: "Adulteración de michtlapic: michín, pescado, tlapic, envuelto, derivado de piqui, envolver tamales en hojas. (Robelo.) m. "Pescadito de los lagos de la altiplanicie que se asa y se envuelve en hojas de maíz en forma de tamal para su venta en los mercados de Méjico". VARS.: mestlapique, mezclapique, meztlapique, etc. (1992, s.v.).

Creo que Alcedo consideró que se trataba de dos peces distintos, por lo que proporcionó la doble lematización y, luego, una descripción más o menos detallada en la entrada de miztlapique, "pez pequeñito" en comparación con el "Peje Rey".

Una inconsistencia más radica en presentar varias entradas en plural, aunque sin necesidad aparente de ello: albures ('juego de cartas'), camellones ('parcela de tierra para cultivar construida sobre el agua') y chalchihuites ('piedra').

\section{Léxico novohispano}

A pesar de los descuidos y errores mencionados, no se puede negar la importancia de este repertorio lexicográfico como el primer intento de ofrecer un panorama objetivo de las realidades americanas. De hecho, según el título completo del Vocabulario y la explicación que lo inaugura, Alcedo reunió las voces usadas en su Diccionario cuyo significado quería precisar para su fácil comprensión. Véanse sus propias palabras al respecto:

Ofrecimos en el Plan de subscripción, que se publicó para este Diccionario, dar al fin de la Obra este Vocabulario, como parte precisa para la inteligencia de muchas voces usadas en aquellos Países: unas que aunque originarias de España, y especialmente de Andalucía, han degenerado allí por la corrupción que ha introducido la mezcla de los idiomas de los Indios; y otras tomadas de éstos, y mal pronunciadas por los Españoles; y sin embargo de que en muchos artículos explicamos el significado de algunas, como ocurren las mismas en otros, y no es posible tener presente el de la Provincia, Pueblo, ó distrito en que se dixo, creímos que sería conveniente reunirlos por orden alfabético para que qualquiera pueda imponerse con facilidad del significado de la voz que no comprenda en los Artículos del Diccionario ${ }^{13}$.

No obstante, en lo que al vocabulario novohispano se refiere, no todas las palabras fueron incluidas en el texto del repertorio enciclopédico; la gran mayoría está ausente de las páginas de su obra, lo cual podría deberse a que el Vocabulario presenta información adi-

13 Cf. Antonio de Alcedo 1789, t. 5, p. 1: "Vocabulario de las voces provinciales de la América usadas en el Diccionario Geográfico-Histórico de ella; y de los Nombres propios de las plantas, aves y animales". 
cional a la del Diccionario y se centra en plantas, aves y animales; su obra de cinco volúmenes, en cambio, tiene como propósito describir los territorios americanos, presentar los datos de sus descubridores, conquistadores, fundadores, obispos, así como dar testimonio de sus desastres naturales. De cualquier modo, toda esta información en conjunto muestra el amplio conocimiento del autor sobre América.

Aunque, como mencionamos líneas arriba, el objetivo de Alcedo en el Vocabulario era recopilar las voces de plantas, aves y animales americanos, los campos semánticos de los vocablos novohispanos recogidos se amplían a árboles (mezquite, ocóte); frutas (chabacano, tepexilote); raíces (castañuela, jalápa, mechoacán); hierbas (morón, quapaxtle); peces (bobo, charál o mistlapic, miztlapique); insectos (cochinilla, grana); minerales (chalchihuites); resinas (chicle, tacamahaca); azúcares (chincate o chancaca, marquesote, piloncillo); bebidas (chinguirito, pulque, purpúra marítima); vestidos típicos (ayate, guepil); enfermedades (matlazahua); pero, además, a las costumbres (albures, barrio, camellones, copal, coyóte, teanguis, xacal o xacale, xicara), aunque por sus definiciones enciclopédicas, la mayoría de los artículos presenta hábitos y tradiciones de los habitantes.

La cantidad de voces novohispanas no es muy considerable ${ }^{14}$. Con base en la metodología establecida, obtuve 53 vocablos concernientes a $8.2 \%$ del total de su lista americana; no obstante, son muy significativos: la mayor cantidad, 37 (69.8\%), corresponde a los de procedencia indígena, concretamente del náhuatl, lo que no sorprende, pues Alcedo se ocupa en detallar los atributos de estas tierras. De hecho, para precisar estas voces, las documenta con diferente escritura; resultado de la distinta pronunciación son tres entradas: chincate o chancaca, giquelite o huiquilitl y xacal o xacale, sin dejar de señalar la variante léxica reunida en un lexema como producto de distintas lenguas originarias: charál (tarasco) o mistlapic (náhuatl). Lo que llama la atención es la poca variedad presentada por el autor, que no siempre recogió variantes empleadas en la época: cacahuate (cacahuete, cacaguate, cacahué o cacahuey); guepil (güipil, huipil, vipil); sopilote (zopilote); tacamahaca (tacamacha, tacamahaca, tacamaca, tacamaja); tecolote (tocolote); teanguis (tiangue, tiánguez, tianguiz); tepeiscuntli (tepe[i]zcuinte, tepeiscuintle, tepeixcuinte, tepeixcuintle, tepescuintle); zenzontli (sinsonte, cenzonte,

${ }^{14}$ Es relativo, ya que no hay un estudio que pudiera consultar en que se proporcione el número de vocablos por zonas o países americanos, por lo que es imposible comparar esta cifra. Seguramente, la tesis de doctorado de Carlos Mayor LóPEz (1991), que se centra en la obra lexicográfica de Alcedo, podría facilitar no sólo estos datos, sino también material valioso acerca de distintos aspectos del Vocabulario; desafortunadamente, no me fue posible consultarla. Además, según ya he mencionado, al no tener acceso a la Bibliotheca americana, no me encuentro en condiciones de saber a ciencia cierta cuántas referencias aludían al Virreinato que nos ocupa y obtener las conclusiones numéricas más concluyentes al respecto. 
cenzontle); xacal (jacal); xicara (jicara), sin mencionar jiquilete para giquelite o huiquilitl (Sala et al. 1977, pp. 17-133; Buesa Oliver y Enguita Utrilla 1992, pp. 73-86). Otro detalle que creo importante señalar es que cuatro voces indígenas que refieren a la flora novohispana en el repertorio de Alcedo son topónimos, por proceder de ciertas regiones: campéche ‘árbol'; jalápa y mechoacán 'raíces'; oaxáca 'especie'.

$\mathrm{Al}$ revisar las voces indígenas en el Corpus diacrónico del español (CORDE) que Alcedo asigna al virreinato, 13 no presentaron ningún caso para la consulta, aunque se buscó el vocablo con sus posibles variantes (ayate, cascalote, chalchihuites, charál o mistlapic, giquilite o huiquilitl, matlazahua, miztlapique, oaxáca, oleacazán, quapaxtle, tepéiscuntli, tepexilote, zenzontli), lo que representa el 35.1\%. En cuanto a los demás vocablos que se documentaron en esta herramienta electrónica, los resultados en su gran mayoría coinciden con los anotados por el ecuatoriano en el Vocabulario, a saber: las voces que consideró privativas de la Nueva España aparecen con este distintivo en el CORDE: cacahuate, chicle, chico zapote, aunque la mayor cantidad de casos es para chicozapote, coyote, mezcal, huipil (güipil no se documenta), mezquite, mitote, ocote, pulque, sopilote (zopilote registra mayor cantidad de resultados), tecolote, xacal/jacal, menos la variante xacale, que no se recoge, y xícara.

En el grupo de vocablos exclusivos de la Nueva España, hubo tres diferencias que me gustaría destacar: mixe presenta un significado distinto del que le atribuye Alcedo, 'el de la lengua hablada por este grupo indígena' y no 'tabaco'; teanguis no arrojó ningún resultado, mientras que la búsqueda de tianguiz y tianguis ofreció varios casos con el mismo sentido, y tecamahaca, como la recoge Alcedo, en el CORDE se registra como voz venezolana, frente a tecamaca, novohispana.

Asimismo, los vocablos que Alcedo compartió con otros territorios americanos, aunque se empleaban en la Nueva España, presentaron los mismos resultados, lo que concuerda con las afirmaciones de Juan Antonio Frago (1999, pp. 241-242) de que muchos nahuatlismos léxicos no son privativos de México, sino que se difundieron por toda Sudamérica por los mismos colonizadores españoles que los llevaron allí: chile, chancaca (su variante chincate no se recoge) ${ }^{15}$, copal, mientras que jalapa y mechoacán extrañamente no documentaron ningún caso novohispano.

La voz campeche, atribuida por Alcedo exclusivamente a la Nueva España, se consigna en el CORDE como vocablo empleado en Perú y las Antillas en la época, mientras que chavacano/chabacano, a diferencia de Alcedo, se documenta en el corpus diacrónico únicamente como vocablo español con el significado de 'grosero'.

15 Marius Sala et al. (1977, p. 51) y Martha Hildebrandt (1961, pp. 226-228) tampoco documentan la variante para dicha voz; sólo recogen el lexema chancaca. 
El resto del repertorio de Alcedo, 16 lemas (30.2\%), son palabras españolas de significado distinto al peninsular que permanecieron invariables en su forma (barrio 'aldea pequeña', en vez de 'distrito de una ciudad'16; bobo 'pez', frente a 'de poco entendimiento'; castañuela 'raíz que sirve para engordar el ganado', frente al 'instrumento musical'; morón 'hierba', y no 'montecillo de tierra'). Otro caso es el de los sufijos diminutivo o aumentativo, que marcaron la diferencia semántica (cochinilla 'insecto', chinguirito 'aguardiente de caña' 17 y marquesote 'azúcar') o dieron origen a otra voz con el mismo sentido: piloncillo 'azúcar', 'dulce'.

De forma mayoritaria, los vocablos novohispanos están representados por unidades simples, aunque Alcedo recoge también dos locuciones: pito real 'pájaro' y purpúra marítima 'licor', cuyas designaciones complejas describen sus principales características.

Al contrastar esta parcela léxica con el CORDE, se observó un cuadro distinto en comparación con los vocablos nahuas, ya que se encontró una coincidencia, sin contar que cinco voces no se registraron en este banco de datos en la misma proporción que las voces indígenas, $31.25 \%$ : chinguirito, morón, pito real, purpúra marítima, quin$t e$, como sustantivo. La coincidencia reside en que el CORDE consignó tres palabras (cachupín, cibolo y piloncillo) como novohispanas, dato que desconcierta, pues este corpus consigna la variante gachupin, no registrada por Alcedo, como privativa de Perú.

En cuanto a las diferencias, seis lexías no presentaron ningún caso novohispano y se recogieron con significados distintos del Vocabulario, de éstas, cinco se restringieron a España: albures ('pez', frente al 'juego'), bobo ('persona tonta' y no 'pez'), barrio ('distrito de una ciudad' y no 'aldea pequeña'), castañuela ('instrumento musical' y no 'raíz'), marquesote ('despectivo de marqués' y no 'azúcar') y camellones, la cual, con concordancias de Chile y Colombia, se muestra con el sentido

${ }^{16}$ Covarrubias (s.v.) indica que esta voz proviene del árabe barr, que significa campo; por eso, el barrio es lo mismo que la casa de campo, de ahí esta adaptación semántica.

17 Joan Corominas y José Antonio Pascual (t. 2, 1984) consideran que chinguirito (s.v.) proviene de la voz española chingar, de la cual dicen: "voz de origen jergal, cuyo significado primitivo parece haber sido 'pelear, reprender', de donde 'fastidiar, estropear' probablemente del gitano čingarár 'pelear', de origen índico; pero no todas las palabras castellanas en ching- derivan de este verbo, pues en América se mezclaron con ellas algunas radicales aborígenes... desde 'fastidiar, estropear' es fácil llegar hasta 'emborrachar', usual en indo-portugués de Goa”. En cambio, Félıx Ramos y DUARTE (1895, s.v.) opina que chinguirito "es término adulterado del bable chigre, tienda de bebidas al por menor. Parece probable que de chigre, por epéntesis, se dice chinguere, y de aquí chinguirito; i del gallego chinca, gota, ó poco de agua ó de algo, se dice chingar (que en Méjico emplean en otro sentido), beber; chingarse, embriagarse; chingado, borracho. Chinca es alteración de chisca, que en gallego significa "gota ó poco de cualquier líquido»". 
de 'división natural de la tierra' y no 'parcela de tierra para cultivar construida sobre el agua'. Cochinilla, aunque se documentó con la misma semántica, a diferencia de Alcedo no se recogió como exclusiva del territorio novohispano, sino que su uso se hizo extensivo a España, Perú y Ecuador.

Si se analizan las definiciones del repertorio novohispano, se observa su desproporción: la mayor parte de los artículos se elaboró detalladamente (bobo, camellones, campeche, copal, cochinilla, cuya explicación, por la importancia de este pequeño insecto del nopal, que desde hace siglos se ha utilizado para teñir de rojo carmín el cuerpo, la ropa, muros y alimentos, es la más extensa al ocupar tres páginas ${ }^{18}$, jalápa, mechoacán, mezquite, pulque, tacamahaca), en tanto que otra, de modo bastante escueto (ayate, barrio, cachupin, chicle, marquesote, mitote, mixe, tecolote, xacal o xacale). Veamos dos ejemplos:

TACAMAHACA (Populus Balsamifera). Resina sólida llamada impropiamente goma, pues se disuelve enteramente en espíritu de vino: es una substancia resinosa, seca y de un olor penetrante: el árbol que la destila por sí mismo ó por incisión hecha en la corteza, se llama Arbor populo similis resinosa altera Tacamahacca foliis crenatis: abunda mucho en la Nueva España: su madera es resinosa, las hojas pequeñas, redondas y dentadas: el fruto que da es del tamaño de una nuez de color encarnado, resinoso y fragante: contiene un hueso semejante al del de Melocotón. Hay dos especies de Tacamahaca en las Boticas y tiendas de Droguistas: la primera que es la mejor y se llama comúnmente Tacamahaca sublime, se traía antes en calabacitos, y es la que destila el árbol espontáneamente: debe estar seca, transparente y que tire á roxo, de olor fuerte y agradable, semejante al de el agua de Labanda y del Ámbar. La segunda es la ordinaria que se saca por incisiones hechas en el árbol: toma varios colores según los pedazos de corteza en que cae, están más ó menos llenos de porquería: de ésta se debe preferir la que se acerca más al olor de la primera: rara vez se debe dar la Tacamahaca interiormente; pero por fuera se usa con freqüencia para calmar los dolores, especialmente si provienen de humores fríos, resuelve y hace madurar los tumores: aplicado al ombligo corrige la pasión histérica, y la sofocación de la matriz: aplicado al estómago lo fortifica y ayuda á la digestión; y un parchecito en la sien alivia el dolor de muelas: también se usa en varias preparaciones, como en el emplasto cephálico odorífero de Charas, en los de Diabotano estomacal, y bálsamo de Fioravanti.

XACAL ó XACALE. Choza de los Indios de la Nueva España.

${ }^{18}$ Lo que concuerda con los datos del CORDE, que, a diferencia de todos los demás vocablos analizados, documentó la mayor cantidad de concordancias, a saber: 113 casos en 48 documentos. 
Esta desigualdad en las definiciones tal vez se deba a que Alcedo consideraba unos vocablos más conocidos que otros, por lo que no creía necesario ahondar en las explicaciones. Recuérdese que la obra estuvo ideada para figurar como anejo del Diccionario y que su autor pensó en la utilidad de recogerlos para, entre otras cosas, presentar el cuadro completo de las realidades americanas. Asimismo, sus definiciones ofrecen las explicaciones por aproximación y semejanza con las realidades europeas para fácil comprensión de los lectores españoles, a quienes está dirigida la obra:

CASTAÑUELA. Raíz... con que ceban para engordar el ganado de cerda, lo mismo que la bellota en Extremadura.

CHAVACANO. Fruta de la Nueva España: especie de Albaricoque, cuyo árbol es también semejante.

CHARÁL ó MISTLAPIC. Nombres sinónimos que dan en la Nueva España al pez Peje Rey...

CHILE. Nombre que dan en Nueva España al pimiento...

MEZQUITE. Especie de algarrobilla silvestre...

OCÓTE. Árbol de la Nueva España, semejante al Pino: las hojas se parecen á las del Cedro...

TECOLOTE. Nombre que dan en Nueva España al Búho.

TEPEXILOTE. ...son como Avellanas pequeñitas de mucha consistencia... ZENZONTLI. Ave del canto de Nueva España semejante al Ruiseñor...

Como Alcedo revisó varias fuentes para su obra, en cuanto a las plantas y animales proporciona sus nombres científicos, según la nomenclatura bimembre concebida por el sueco Carlos Linneo en 1753 , cuya versión en español seguramente consultó nuestro autor ${ }^{19}$ :

CAMPÉCHE (Hematoxilum Campechianum). Palo de árbol, y género de la clase decandrya monogynia...

CIBOLO (Bos Bisson). Especie de Toro montaraz de la provincia de Cinaloa en la América Septentrional...

Y no sólo esto, sino que Alcedo, como mencioné con anterioridad en cuanto a la referencia de Francisco Hernández, revisó minuciosamente los trabajos de otros botánicos de renombre y ofrece amplia información al respecto, citándolos como las autoridades en la materia que sustentan su obra:

19 (Carl von Linnet) Caroli Linnæi, Species plantarum, exhibentes plantas rite cognitas, ad genera relatas, cum differentiis specificis, nominibus trivialibus, synonymis selectis, locis natalibus, secundum systema sexuale digestas..., Holmiæ (Estocolmo), Impensis Laurentii Salvii, 1753, 2 ts. Hay una edición de la época en español: Parte práctica de botánica del caballero Carlos Linneo: que comprehende las clases, órdenes, géneros, especies y variedades de las plantas, con sus caracteres genéricos y específicos, sinónimos más selectos, nombres triviales, lugares donde nacen y propiedades, traducida del latín al español e ilustrada por Antonio Paláu y Verdéra, Imprenta Real, Madrid, 1784-1788, 8 ts. 
JALÁPA (Mirabilis Jalapa). Raíz y género de la clase pentandria monogynia, cuya corola es formada en embudo: el cáliz está debaxo del fruto, y el nectario es globular incluyendo el germen. Hay tres especies y todas nativas de América. Tournefort ${ }^{20}$ y Linneo quieren que la raíz de esta planta sea la Jalapa de las Boticas; pero Houstón ${ }^{21}$ dice que es la raíz de una especie de Convolvulus...

Alcedo también se considera especialista, por lo que en otros artículos, cuando no está de acuerdo con los testimonios de las autoridades botánicas, lo precisa:

MECHOACÁN (Convolbulus Mechoacan). Raíz de una planta á quien Hernández da el nombre de Taquach, y dice aunque impropiamente que es especie de Brionya...

PITO REAL. Nombre que dan en Nueva España al páxaro Tulcán, véase esta voz. Mr. Bomare ${ }^{22}$ equivoca en su descripción á éste con el Carpintero, que son distintos...

Pero lo que más podemos apreciar del Vocabulario es el amplio conocimiento de las costumbres novohispanas, evidenciado en las explicaciones de las voces. Aunque Alcedo radicó principalmente en Ecuador y Panamá y pasó una breve estadía en Cartagena de Indias, sus múltiples viajes le permitieron acercarse al diario acontecer novohispano y sus peculariedades:

ALBURES. Juego de cartas semejante al de parar, muy usado en Nueva España, donde se juega con exceso.

${ }^{20}$ Joseph Pitton de Tournefort (1656-1708). Botánico francés. Realizó exploraciones en Los Pirineos, España y Portugal. Autor de Éléments de botanique, ou, Méthode pour connaître les plantes, Imprimerie Royale, Paris, 1694. Cf. Frank A. Stafleu y RICHARD S. CoWAN 1983, t. 4, s.v.

${ }^{21}$ William Houstoun (1695-1733). Viajero y explorador inglés que recogió muestras botánicas en territorios americanos y las trasladó a Inglaterra. Con sus noticias se publicó en Londres, en 1794, Reliquia Houstouniana: Seu plantarum in America Meridionali a Gulielmo Houstoun M.D.R.S.S. collectarum icones manu propria are incisa; cum descriptionibus e schedis ejusdem in bibliotheca Josephi Banks, baroneti, R.S.P. asservatis. El propio Linneo utilizó con frecuencia sus hallazgos tras recibir las notas y grabados de Houstoun en 1736. Cf. Frank A. Stafleu y Richard S. Cowan 1979, t. 2, s.v.

${ }^{22}$ Jacques-Christophe Valmont de Bomare (1731-1807). Naturalista y mineralogista francés, autor de Dictionnaire raisonné universel d'histoire naturelle... [contenant l'histoire des animaux, des végettaux et des minetraux, et celle des corps célestes, des météores, E̋ des autres principaux phénomenes de la nature; avec l'histoire et la description des drogues simples tirées des trois regnes; et le détail de leurs usages dans la médecine, dans l'économie domestique $\mathcal{E}$ champestre, et dans les arts $\mathcal{E}^{\mathcal{O}}$ mettiers: plus, une table concordante des noms latins, $\mathcal{E}$ le renvoi aux objets mentionnés dans cet ouvrage], publicado en París por Lacombe Libraire, en 15 volúmenes, a partir de 1764. En el mundo de la nomenclatura botánica, se le reconoce como Valmont. Cf. Frank A. Stafleu y Richard S. Cowan 1986, t. 6, s.v. 
AYATE. Manta de algodón con que se cubren los Indios en las Provincias de Nueva España.

BOBO. Pez muy común en los ríos de Nueva España y América Septentrional: tiene palmo y medio de largo, y con medio grueso: la piel negra y sin escamas, y la carne sin espinas: le dan el nombre de bobo por la facilidad con que se dexa matar á palos en las orillas, acudiendo en tropas á las migas de pan que echan; y muchas veces sólo con mover el agua.

CHICLE. Resina que destila el árbol del Zapote, y le dan este nombre en Nueva España, estimándolo como singular específico para varios males ${ }^{23}$. MIZTLAPIQUE. Pez pequeñito y muy regalado que abunda en la Laguna de México: es del tamaño de un dedo, y semejante á los dorados.

OCÓTE. Árbol de la Nueva España, semejante al Pino: las hojas se parecen á las del Cedro, da de sí mucha resina ó goma, y de sus ramas hacen los Indios teas para alumbrarse...

Sus explicaciones, además, se enriquecen con anécdotas y detalles curiosos:

CHALCHIHUITES. Piedra verde que se encuentra en las minas de plata del Reyno de Nueva Galicia en la América Septentrional, á la qual atribuyen la virtud de quitar el dolor de ceática. Los antiguos Mexicanos estimaban mucho estas piedras que varían en los colores, aunque la de más aprecio es la verde, de la qual hay una Ara grande en la Iglesia catedral de la Puebla de los Ángeles. COCHINILLA. ...Los principales parages de la América, en que se cultiva la Cochinilla son Oaxaca, Tlaxcala, Cholula, Nueva Galicia, en Nueva España, en Guatemala, y Chiapa, en Loxa y Ambato, en el reyno de Quito, y en Tucumán, y algunas Provincias del Perú; pero en Oaxaca es donde se coge la mayor cosecha, y forma un ramo de comercio muy considerable, porque alli se han dedicado casi todos los Pueblos á ello.

GUEPÍL. Vestido que usan las Indias en Nueva España de una tela texida de algodón de que hacen mucho en la Provincia de Villalta.

QUAPAXTLE. Yerba aromática y olorosa de Nueva España, que cultivan y usan mucho, especialmente en la Jurisdicción de Malinalco para llevarla á México y otras partes.

ZENZONTLI. Ave del canto de Nueva España semejante al Ruiseñor: es de el tamaño de un Tordo, y de color ceniciento: tiene muy dulce y suave el canto y con diferentes variaciones, por lo qual le dan este nombre, que en el idioma Mexicano significa quatrocientas voces.

En este sentido, la voz pulque me parece sintomática, por lo que la transcribo completamente:

PULQUE. Bebida muy común en Nueva España: es el licor fermentado de El Maguey, que se hace de este modo: quando la planta tiene seis ó siete años le cortan el cogollo y con un instrumento á modo de cuchara

${ }^{23}$ Considérese también lo que dice en relación con tacamahaca (cf. supra) y sus propiedades para paliar diversidad de malestares. 
de acero afilada por los extremos que llaman Ocascle, hacen un hoyo en el tronco de la planta, y allí va destilando una agua miel clara, y no desagradable al gusto, la qual cogen dos veces al día por tarde y mañana como en cantidad de dos quartillos: lo echan en tinajas mezclando algunas yerbas y frutillas con que fermenta luego, y se puede beber; pero no guardarse más que un día ó dos porque se pierde. Esta bebida embriaga, suple la falta de vino, y los Indios la usan desde el tiempo de su gentilidad. Entran cada mañana en México de ochenta á noventa mil quartillos de Pulque, y á las dos de la tarde no se halla sino en dos Pulperías de las 42 en que se vende: y está mandado que se reserve en ellas para el caso de necesitarse por remedio, pues lo usan en muchos casos: paga cada carga un real de derecho de entrada al Rey, cuyo producto es un ramo muy considerable de la real Hacienda.

En las páginas de esta obra, en el plano léxico, se siente la simpatía y hasta admiración de su autor por el mundo americano (bainilla, boguilla, cardenal, chacarandá, chiguire, chirimoya, diuca, getúdo, guayába, leche miel, maitén, nazaréno, etc.) al enaltecer las virtudes de alimentos, materias primas, etcétera:

COCHINILLA. ...pero la pulpa ó médula [de la tuna] es tan encarnada que tiñe la orina de este color á los que la han comido: cosa que admira y aun asusta á los que no están acostumbrados, y sin embargo hay pocas frutas tan sanas y agradables...

COPAL. ... se usa como uno de los mejores barnices...

MIZTLAPIQUE. Pez pequeñito y muy regalado que abunda en la Laguna de México...

OAXÁCA (Polvos de). Muy estimados por su fragancia y buen gusto para echar en el chocolate...

OLEACAZÁN. Planta... celebrada por su maravillosa virtud para restaurar las fuerzas perdidas...

Sus explicaciones abundan en adjetivos y comparaciones y se llenan de superlativos para subrayar las bondades novohispanas:

CASCALOTE. Planta de Nueva España que sirve como principal ingrediente para dar color..., para hacer un negro atezado y perfecto, por lo qual es yerba muy útil...

CIBOLO. ...se distingue del común, en que tiene la cerviz poblada de una lana muy larga y suave: su carne es muy gustosa y apetecida de los naturales. COPAL (Copalifera). Goma que se saca por incisión de un árbol muy grueso que tiene las hojas largas, anchas y puntiagudas, y el fruto semejante al membrillo. Esta goma es dura, amarilla, lustrosa, y transparente, y puesta al fuego exhala un olor semejante á el de Oliván: se ablanda, se liquida, y se usa como uno de los mejores barnices...

MORÓN. Especie de yerba silvestre y viciosa que se cría en los Islotes llamados Alacranes en el seno ó Golfo Mexicano, en que hay muchísimos topos. 
En estas descripciones se ve reflejado el entusiasmo del autor que atribuye a las ventajas del Virreinato un brillo especial; además de los otros vocablos aducidos, un ejemplo más:

COCHINILLA. Género de insecto del orden cleoptera...: el famoso animal tan estimado en todas partes del mundo por la incomparable hermosura de su color encarnado, con que se tiñe la seda, el lino, el algodón, y la lana... la flor es pequeña, de encarnado brillante, y de la figura de un botón, de la qual nace la Tuna, que es el nombre del fruto, y conforme crece éste se marchita la flor, hasta que se cae: quando está maduro el higo ó tuna, su corteza exterior se vuelve blanca, pero la pulpa ó médula es tan encarnada que tiñe la orina de este color á los que la han comido: cosa que admira y aun asusta á los que no están acostumbrados, y sin embargo hay pocas frutas tan sanas y agradables... el jugo de esta planta, que es lo único que comen, se convierte en su substancia, que en vez de ser fluida y aquosa, es un hermoso color carmesí.

No obstante esta fascinación, no puede dejar de mencionarse otro aspecto importante que se deja ver en todo el Vocabulario y también en esta parcela léxica novohispana: el prejuicio de Alcedo hacia los indios, naturales de estas tierras, y los negros. Sin hacer una revisión exhaustiva encuentro varios artículos que lo demuestran, como banano 'alimento general de los negros y de los indios que lo comen en lugar del pan'; bozal 'negro que no entiende nada ni tiene idea de costumbres, artes, oficios, ni religión y es irracional por su torpeza e ignorancia'; changamé 'ave que comen los negros'; chicha 'bebida de los indios y gente de color'; cholo 'indio con cultura por haberse criado entre los europeos y hablar español'; cimarrón 'negro que huye de la casa de su amo por no trabajar o por no sufrir castigo por la falta que ha cometido'; guarapo 'vino de los negros'; otoe 'alimento de los indios porque no les cuesta trabajo su fructificación'; nigua 'pulga que ataca a los negros, gente de color y los cerdos'.

Hay otros vocablos, en cambio, que refieren a los usos de "la gente de distinción”, según palabras de Alcedo: papas 'alimento, además de los indios y de los negros, aun de la gente de distinción'; $p a p a-$ $y a$ 'fruta que se come a las once para refrescar'; pina 'fruta gustosa en América y Europa'. Esta actitud se percibe también en el léxico novohispano para aludir a indios y a negros, a quienes atribuye enfermedades propias (matlazahua) y remedios para su alivio (jalápa), además de vestimenta (ayate y guepil), bailes (mitóte), comida (mezquite), bebida (pulque), vivienda (xacal o xacale), parcelas de tierra (camellones), trabajos que realizan (cochinilla). Se entiende que, como parte de su tarea lexicográfica, el autor haya referido las actividades, costumbres, gustos, enfermedades, y hasta designaciones que algunos debían sobrellevar, tanto de indígenas como de negros; sin embargo, las descripciones reflejan su condición social y su actitud de espa- 
ñol, aunque nacido en América, hacia esta parte de la población en la cual, como hombre de su tiempo y según su educación, ve normal, y hasta lógico, además de que haya enorme desigualdad, que indios y negros sufran el maltrato impuesto por los blancos de acuerdo con la lógica política derivada de la Conquista, la cual perduró durante todo el poderío español. A esta actitud corresponde, pues, que algunos artículos lexicográficos pretendan demostrar, como el de nigua arriba mencionado, que hay enfermedades que sólo atacan a indios y a negros; por tanto, los remedios también son efectivos exclusivamente en ellos:

JALÁPA (Mirabilis Jalapa). Raíz y género de la clase pentandria monogynia, cuya corola es formada en embudo...: es muy buen purgante especialmente para los Negros...

MATLAZAHUA. Enfermedad ó epidemia propia de la Nueva España: es una especie de dolor de costado muy contagioso, que quando reyna hace increíble estrago en los Indios.

Del mismo modo, hay ciertos alimentos que estiman particularmente los nativos, como el cibolo (cf. supra), cuya carne "es muy gustosa y apetecida de los naturales". Pero si las enfermedades y los gustos por ciertas viandas difieren, con mayor razón las faenas diarias. La entrada que sigue es muy reveladora en este respecto, como en muchos otros arriba anotados, ya que el trabajo duro está a cargo de los indios, pero al de otros, su provecho, quienes incluso, claro está, pueden verse en riesgo de perderlo:

COCHINILLA. En los meses de Mayo y Junio está la planta en su más vigoroso estado, y es la estación propia para depositar en ella los huevos casi imperceptibles, lo qual hacen los Indios con suma paciencia, y en el corto espacio de dos meses llega al estado que hemos dicho; pero mientras, está expuesta á muchos riesgos, porque los vientos fuertes del Norte se llevan los huevos, y lo mismo sucede con los aguaceros recios, y los yelos secan y destruyen las hojas, dexando sólo al cultivador el recurso de hacer fogatas á cierta distancia, y llenar el ayre de humo, con que suelen preservarlas de las inclemencias del tiempo: no padecen menos por los páxaros de varias especies que gustan mucho de comer estos insectos, y por los gusanos que se crían en las Nopaleras, y á pesar del cuidado que se pone en uno y otro pierden mucho los hacendados.

Una actitud semejante se observa en el artículo cachupin 'nombre que dan en Nueva España á los Europeos'; es decir, a quien llaman con este apelativo no es español sino, con sentido más amplio, cualquier habitante europeo, lo que contradice el significado que ofrece el Diccionario de la lengua castellana en su edición de 1780: "El español que pasa y mora en Indias, donde se llama GACHUPIN. Es 
voz muy usada en Andalucía”. Es evidente la carga negativa de este vocablo, pues no alude únicamente a los oriundos de España que marchan a las Indias, sino también a los incultos, según Kany (1969, p. 34): "gachupin, también cachupin, al parecer del antiguo cachopo 'tronco seco', aplicado a los primeros colonos españoles por la ignorancia de los recién llegados respecto a las cosas americanas, y ahora se aplica especialmente a determinado tipo de español inculto". Quizás Alcedo cambió esta definición por no presentar a los españoles de tal manera; no hay que olvidar que sus lectores mayoritariamente eran de la Península.

\section{Conclusiones}

Tras la revisión de 53 voces novohispanas contenidas en el Vocabulario de las voces provinciales de la América usadas en el Diccionario GeográficoHistórico de ella, se puede concluir que, aunque la obra de Alcedo no se circunscribe de modo particular a lo que hoy es el territorio mexicano, contiene valiosa información de esta área, representada preponderantemente por el léxico indígena de origen náhuatl (37 vocablos: $69.8 \%$ ) y, en menor grado, por los vocablos patrimoniales que experimentaron el cambio semántico fuera de España (16 voces: $30.2 \%$ ). Datos parecidos se obtuvieron del CORDE, que coincide con el repertorio amerindio en cuanto a la atribución de su empleo diatópico y en el significado; y en lo que toca a las voces españolas, éstas se documentaron con significado distinto al peninsular para describir las realidades del territorio novohispano.

A pesar de anunciar que en la obra se presentarían datos sobre la flora y la fauna americanas, en el caso particular de la Nueva España, Alcedo amplió los campos semánticos a la indumentaria, alimentación, bebidas, vivienda, enfermedades, así como a las costumbres y la vida de la época, lo que permite obtener una visión de la fascinante realidad novohispana que recreó su autor. Empero, al describir usos y tradiciones novohispanos de finales del siglo XVIII, se observan actitudes y prejuicios que, no obstante, en ningún momento opacan la enorme simpatía y hasta admiración del autor por el mundo virreinal; así se percibe en el tratamiento de los artículos correspondientes, que superan cualquier referencia negativa. Por tanto, su visión en conjunto del vocabulario novohispano puede considerarse objetiva de algún modo, toda vez que es menos proclive a lo pintoresco que la de sus antecesores. Precisamente por eso, ya que no es un vocabulario solamente, sino el reflejo de la mirada de Alcedo, se convirtió en fuente obligada de los posteriores repertorios lexicográficos, sobre todo del siglo xIX. 


\section{REFERENCIAS}

Alcedo, Antonio de 1786. Diccionario geográfico-histórico de las Indias Occidentales ó América: es á saber: de los Reynos del Perú, Nueva España, Tierra Firme, Chile, y Nuevo Reyno de Granada. Con la descripción de sus provincias, naciones, ciudades, villas, pueblos, ríos, montes, costas, puertos, islas, arzobispados, obispados, audiencias, virreynatos, gobiernos, corregimientos, y fortalezas, frutos y producciones; con expresión de sus descubridores, conquistadores y fundadores: conventos y religiones: erección de sus catedrales y obispos que ha habido en ellas: y noticia de los sucesos más notables de varios lugares: incendios, terremotos, sitios, é invasiones que han experimentado: y hombres ilustres que han producido, Imprenta de Benito Cano, Madrid, t. 1, https:/ /archive.org/ stream/ diccionariogeogr06alce\#page/ n25/mode/2up [consultado el 12 de septiembre de 2016].

Alcedo, Antonio de 1789. "Vocabulario de las voces provinciales de la América usadas en el Diccionario geográfico-histórico de ella; y de los nombres propios de las plantas, aves y animales", en Diccionario geográfico-histórico de las Indias Occidentales ó América..., Imprenta de Manuel González, Madrid, t. 5.

Alvar EzQuerra, Manuel 2005. "La lexicografía monolingüe del siglo xviII", en Biblioteca de Recursos Electrónicos de Humanidades E-exceLence para red de comunicaciones en Internet, Liceus, Madrid, pp. 2-18.

Ayala, Manuel José De 1995 [1751-1777?]. Diccionario de voces americanas. Pres. y ed. Miguel Ángel Quesada Pacheco, Arco/Libros, Madrid.

Barros Arana, Diego 1863. "Biografía americana: Don Antonio de Alcedo", Revista de Buenos Aires. Historia Americana, Literatura y Derecho, 2, 5, pp. 492-501.

Becerra, Marcos E. 1984 [1954]. "1 ${ }^{a}$ parte. V. Plantas, Adiciones", en Rectificaciones y adiciones al DRAE, $3^{\mathrm{a}}$ ed. Prol. Francisco J. Santamaría. Pref. e índice alfabético de Francisco Valero Becerra, SEP, México.

Buesa Oliver, Tomás y José María Enguita Utrilla 1992. Léxico del español de América. Su elemento patrimonial e indígena, Mapfre, Madrid.

Cabrera, Luis 1974 [1954]. Diccionario de aztequismos, Oasis, México.

CORDE: Real Academia Española: Banco de datos [en línea]. Corpus diacrónico del español, http://rae.es

Corominas, J. y J.A. Pascual 1984-1991. Diccionario crítico etimológico castellano e hispánico, Gredos, Madrid, 6 ts.

Covarrubias Orozco, Sebastián de 1993. Tesoro de la lengua castellana o española (primer diccionario de la lengua 1611), Alta Fulla, Barcelona.

Flores Olvera, M. Hilda. "Presentación de la versión electrónica de la Historia de las plantas de Nueva España de Francisco Hernández, edición 1942-1946 por el Instituto de Biología, UNAM", http://www.ibiologia.unam.mx/ plantasnuevaespana/prologo.html [consultado el 16 de junio de 2017].

Flores Olvera, M. Hilda y Roberto Lindig-Cisneros 2005. "La Lista de nombres vulgares y botánicos de árboles y arbustos propicios para repoblar los bosques de la República de Fernando Altamirano y José Ramírez a más de 110 años de su publicación", Revista Mexicana de Biodiversidad, 76, pp. 11-35.

Frago Gracia, Juan Antonio 1999. Historia del español de América. Textos y contextos, Gredos, Madrid.

Haensch, GÜNTHer 1994. "Dos siglos de lexicografía del español de América: lo que se ha hecho y lo que queda por hacer", en Unidad y variación léxicas del español de América. Eds. Gerd Wotjak y Klaus Zimmermann, Vervuert-Iberoamericana, Frankfurt/M.-Madrid, pp. 39-82.

Hernández, Francisco 1942-1946 [1571-1576]. Historia de las plantas de Nueva España, Imprenta Universitaria, México, 3 ts. 
Hildebrandt, Martha 1961. La lengua de Bolívar. T. 1: Léxico, Universidad Central de Venezuela, Caracas.

Kany, Charles E. 1969. Semántica hispanoamericana. Trad. Luis Escolar Bareño, Aguilar, Madrid.

LERNER, IsAÍAs 1971. "The Diccionario of Antonio Alcedo as a source of enlightened Ideas", en The Ibero-American Enlightenment. Ed. A. Owen Aldridge, University of Illinois Press, Urbana, pp. 71-93.

LERNER, Isaías 1982. "Sobre dialectología en las letras coloniales: el Vocabulario de Antonio de Alcedo”, Sur, 350/351, pp. 117-129.

LERNER, IsAíAs 1997. "La colonización española y las lenguas indígenas de América”, Colonial Latin American Review, 6, 1, pp. 7-15.

Martínez, Maximino 1994 [1927]. Catálogo de nombres vulgares y científicos de plantas mexicanas, Fondo de Cultura Económica, México.

Mayor López, Carlos 1991. La obra lexicográfica de Antonio de Alcedo (1735-1812), tesis, University of New York, Albany.

Molina, Alonso DE 2001 [1571]. Vocabulario en lengua castellana y mexicana y mexicana y castellana, $4^{\mathrm{a}}$ ed. Est. prel. de Miguel León-Portilla, Porrúa, México.

Moreno, Roberto 1970. Reseña de "Antonio de Alcedo, Bibliotheca americana. Catálogo de los autores que han escrito de la América en diferentes idiomas y noticia de su vida y patria, años en que vivieron y obras que escribieron, compuesta por el mariscal de campo D... gobernador de la Plaza de la Coruña. Año de 1807, Quito, Publicaciones del Museo Municipal de Arte e Historia, 1964, 2 ts.”, Boletín del Instituto de Investigaciones Bibliográficas, 3, pp. 219-220.

O’Gorman, Edmundo 1985. Historia de las divisiones territoriales de México, $6^{\mathrm{a}}$ ed., Porrúa, México.

ONís, José DE 1951. “Alcedo’s Bibliotheca americana”, The Hispanic American Historical Review, 31, 3, pp. 530-541.

Pérez-Bustamante, Ciriaco 1967. "Estudio preliminar. Don Dionisio y Don Antonio de Alcedo y Herrera", en Antonio de Alcedo, Diccionario geográfico de las Indias Occidentales o América, Atlas, Madrid, t. 1, pp. ix-xxxix.

Ramos y Duarte, Félix 1895. Diccionario de mejicanismos: colección de locuciones i frases viciosas, con sus correspondientes críticas $i$ correcciones fundadas en autoridades de la lengua: máximas, refranes, provincialismos $i$ remoques populares de todos los estados de la República mejicana, Imprenta de E. Dublán, Méjico.

Real Academia Española 1780. Diccionario de la lengua castellana reducido á un tomo para su más fácil uso, Joaquín Ibarra, Madrid.

Sala, Marius et al. 1977. El léxico indígena del español americano. Apreciaciones sobre su vitalidad, Editura Academiei Romåne-Academia Mexicana, Bucarest.

Santamaría, Francisco Javier 1992 [1959]. Diccionario de mejicanismos, $5^{\mathrm{a}}$ ed., Porrúa, México.

Simēon, Rēmi 1981 [1885]. Diccionario de la lengua náhuatl o mexicana. Trad. Josefina Oliva de Coll, Siglo XXI, México.

Stafleu, Frank A. \& Richard S. Cowan 1976-1988. Taxonomic literature. A selective guide to botanical publications and collections with dates, commentaries and types, $2^{\mathrm{a}} \mathrm{ed}$., Scheltema \& Holkema, Utrecht, Bonn, 8 ts.

Zaldumbide, Gonzalo 1960. "Antonio de Alcedo", en Prosistas de la Colonia: siglos XV-XVIII. Est. y sel. de Miguel Sánchez Astudillo, J.M. Cajica, Puebla (México), pp. 528-545. 